\title{
THE CAPABILITIES OF 3D GEOSPATIAL TECHNOLOGIES IN THE DECISION- SUPPORT PROCESS FOR DESIGN, CONSTRUCTION, AND EMPLOYMENT OF ENGINEERING STRUCTURES
}

\author{
V. Seredovich ${ }^{1}$, K. Vach ${ }^{2}$, R. Shults ${ }^{3}$ \\ ${ }^{1}$ Siberian State University of Architecture and Civil Engineering, Novosibirsk, Russian Federation - v.seredovich@list.ru \\ ${ }^{2}$ EuroGV, spol. s r. o., Rudná, Czech Republic - vach@eurogv.cz \\ ${ }^{3}$ Research Institute of Geodesy, Topography, and Cartography, Zdiby, Czech Republic-shultsrv@gmail.com
}

Commission V, WG 7

KEY WORDS: Terrestrial Laser Scanning, Complete Control, BIM, Decision-support Process, Engineering Structure.

\begin{abstract}
:
The presented paper is concerned with the capabilities of 3D geospatial technologies in the decision-support process for the design, construction, and employment of engineering structures. Among the various geospatial technologies, the primary stress is made on terrestrial laser scanning (TLS). Despite the widespread application of TLS, its opportunities are not studied thoroughly. A vast volume of studies is dedicated to accuracy, processing workflow, and modeling by TLS data. However, only scanty research considers the TLS technology and data from an ordinary civil engineer's point of view. This study attempts to fill this gap. Covered topics are analysis of the current trends of measurement technologies; in-depth analysis of laser scanning results as a source of new unique data; laser scanning for industrial applications; laser scanning and BIM integration. Except for the mentioned topics, the new concept of the complete control of geometric parameters during the construction and operation of engineering structures is introduced. Complete control plays an indispensable role in the decision-support process during the building life cycle and therefore is an inherent part of any BIM. A description of the steps of complete control and its different applications for civil engineering is given. The decisionsupport process is addressed for different structures, e.g., roads, civil and industrial structures, oil and gas industry objects, etc. Moreover, complete control is considered for the various stages of a building life cycle, from design to demolition. The results provide convincing evidence that the complete control by TLS data has a prominent role in the decision-support process for civil engineering.
\end{abstract}

\section{INTRODUCTION}

In recent years, 3D geospatial technologies have taken a leading position in civil engineering (Berenyi et al., 2009, Berenyi et al., 2010, Ninkov et al., 2010). The surveyors, photogrammetrists, and GIS engineers have been exerting many efforts to study such technologies as close-range and UAV photogrammetry, terrestrial laser scanning, GNSS, and so on for the last years. Considerable research attention has been directed toward design, accuracy, data processing, and modeling. All of the mentioned research is very important for the geospatial industry. The last decades have seen an increased interest in various measuring equipment and its opportunities from the civil engineering hand (Aryan et al., 2021, Hu et al., 2021). This tendency has been invoked by recent developments and refinements in the measuring equipment industry, namely:

- $\quad$ minimizing the sizes of measuring instruments - weight and energy consumption reduction;

- $\quad$ increasing the speed of measurements;

- improving measurement accuracy;

- extension the operation temperature range;

- integration of TLS and photogrammetry, TLS and

GNSS, TLS and total station, TLS and inertial systems, etc.; effective preliminary processing of measurements;

- data transfer via the internet.

- fast and reliable data filtering and registration;

- fusion of measuring equipment and means of data processing.

These features need the following examination and study. At the same time, those features facilitate the usage of 3D geospatial technologies by civil engineers. Today, civil engineers can get by without a surveyor on the construction site in many cases. However, there is limited research investigating the capabilities of 3D geospatial technologies in the decision-support process for the design, construction, and employment of engineering structures. Previous studies have disregarded the role and requirements of ordinary civil engineers and architects concerning geospatial technologies. The vast majority of the works in this area have focused on specific problems of geospatial science. That fact had a negative effect on the adequate application of geospatial technologies in civil engineering. As a result, civil engineers and architects cannot comprehend the role of 3D geospatial technologies in their tasks, especially for such a modern concept as BIM (Mill et al., 2013, Karagianni, 2017, Wu et al., 2022). So, the paper's first goal is to shed light on the liaison between 3D geospatial technologies and the decision-support process in civil engineering. The advantages of 3D geospatial technologies will be considered, and hands-on recommendations will be delivered.

As one may notice that the advanced part in $3 \mathrm{D}$ geospatial technologies takes TLS. The new concept of the complete control of geometric parameters during the construction and operation of engineering structures was suggested based on miscellaneous projects (Shults et al., 2021). The core of the complete control is TLS data. To understand that concept, it is necessary to comprehend the role of complete control at the different stages of a building life cycle. Therefore, the paper's second aim is to present the complete control concept by TLS and the discussion of the pros and cons of this concept.

The paper is divided into five sections. Section two provides an overview of laser scanning results as a source of new unique data. Section three deals with TLS for industrial applications and BIM 
integration. Section four addresses the concept of complete control, and section five outlines some conclusions.

\section{TLS AS A SOURCE OF NEW UNIQUE DATA}

\subsection{Main Tendencies Overview}

Yet the title "terrestrial" means something directly referenced to the ground, but it does not mean that terrestrial laser scanners cannot be used for various mobile applications. Under such an assumption, today, one may stand out different cases of laser scanning, namely: terrestrial laser scanning itself; lidars (with UAV as the main carrier); mobile laser scanning (car or any other vehicle-based); backpack-based laser scanning. So, it is correct to treat all the listed above technologies as particular cases of TLS. Any of these technologies can be a data source for different civil engineering applications. Despite the various options of TLS, all variants inherent standard features of data processing: automated scan registration; automated filtering, vectorization, and data comparison; multiple data exchange formats; integration with BIM products. However, what makes TLS data so useful for civil engineering?

\subsection{Source of New Unique Data}

First of all, it is necessary to determine the advantages of TLS data. Analysis of the benefits of TLS is made from the civil engineer's point of view, and some of them may seem to be evident or unworthy for surveyors but are of importance for engineers. It is worth emphasizing the following advantages: - $\quad$ data are similar to the picture but with 3D metrics; - $\quad$ measurement results are given in one file;

- $\quad$ after fast processing, the data file can be immediately transferred to the software for design, comparison with the project, or other processing;

- $\quad$ measurement results have unique properties: reliability (what I see is what I get), completeness (there is an opportunity to consider the details from different angles), continuity, transparency (allows penetration through surfaces in space and even in time - monitoring cases), the possibility of automated processing and transfer, sufficient accuracy, which allows obtaining unique information about the object;

completely paperless;

allows performing any measurements (even the most incredible ones).

Thanks to these features, TLS data have built a bridge between outdated design and construction technologies in civil engineering and state-of-the-art approaches that are an inseparable part of BIM. This process means total transfer to 3D data that in turn means no need to:

- $\quad$ create drawings in $2 \mathrm{D}$;

create topographic maps;

carry out discrete field measurements (line lengths, elevations, angles);

carry out intermediate work on drawing, transformation, etc., which introduces additional errors.

Moreover, thanks to technology development, the cost of creating three-dimensional models is much cheaper than two-dimensional drawings. And last but not least, the results immediately become ready for full integration with BIM.

The appearance of such a product has led to fundamental changes in design, construction, and operation. Today, TLS data can be employed for:

Process control.

Ensuring processes.

Accounting.
Management.

Condition assessment.

Modeling and forecasting.

Let's embark on the consideration of various TLS applications in line with the major tasks of civil engineering.

\section{TLS FOR INDUSTRIAL APPLICATIONS AND BIM INTEGRATION}

\subsection{Design}

The first case of TLS application for design is highway reconstruction. This is a case of roundabout reconstruction. The initial data for the reconstruction included just paper drawings and construction specifications. Applying TLS to obtain detailed information and a 3D model for the following design was decided. The workflow had the next steps: geodetic network creation, scanning the roadway and curbs, data processing, and data preparation for designers. The final product had a form of BIM with geometric and semantic information (Fig. 1). It is worth mentioning that TLS data were accompanied by underground surveying. So that, the BIM had the whole set of data concerning above and underground communications.

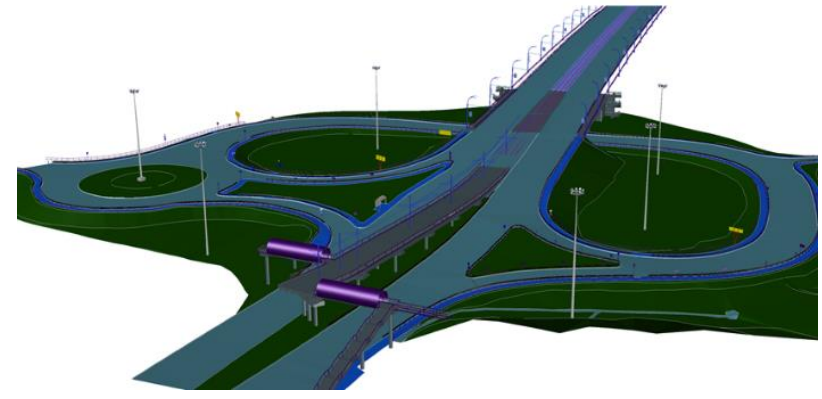

Figure 1. 3D model of the highway for design by TLS data.

It was found out that by obtaining more complete data on the surface of the roadway and curbs, the project's cost was reduced by up to $12 \%$. With the same price list, traditional surveys can be replaced by laser scanning with higher efficiency. These are the main outputs for civil engineers.

The second case is data preparation for building reconstruction. Below are given some sample cases of data gathering for reconstruction. In each case, the feature is the new object embedded into the existing structure, presented as a point cloud, according to the design project. (Fig. 2, Fig. 3, Fig. 4).

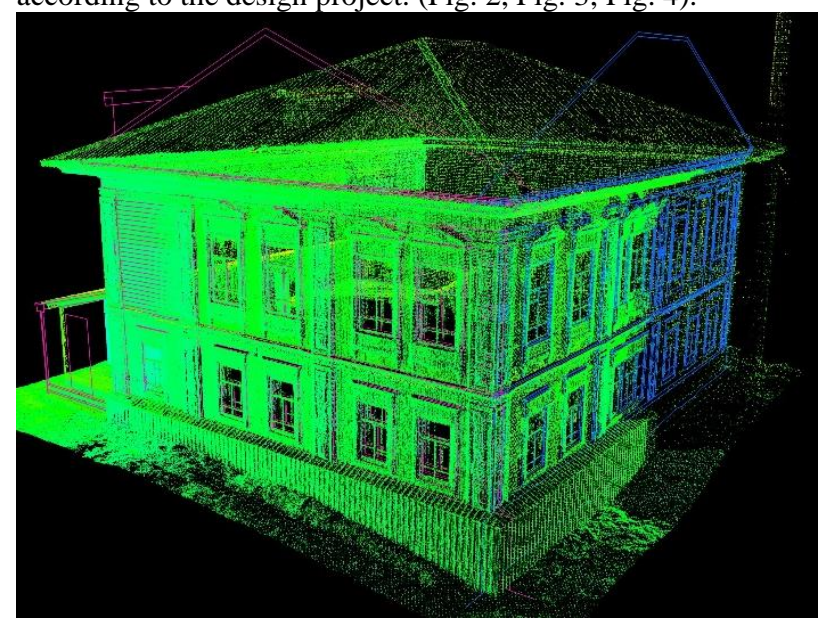

Figure 2. 3D point cloud of a historical building with design elements.

The main conclusions upon accomplishing these projects are that the cost of scanning is commensurate with the geodetic 
measurements, but the quality of the product is much higher. Significantly, graphic manual work with drawings is totally excluded, and the design is based on the actual situation and not some archive data.

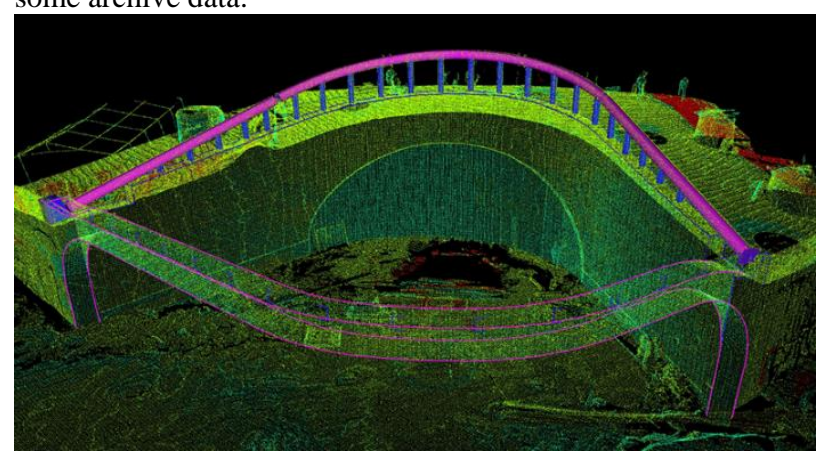

Figure 3. 3D point cloud of the bridge structure with design objects.

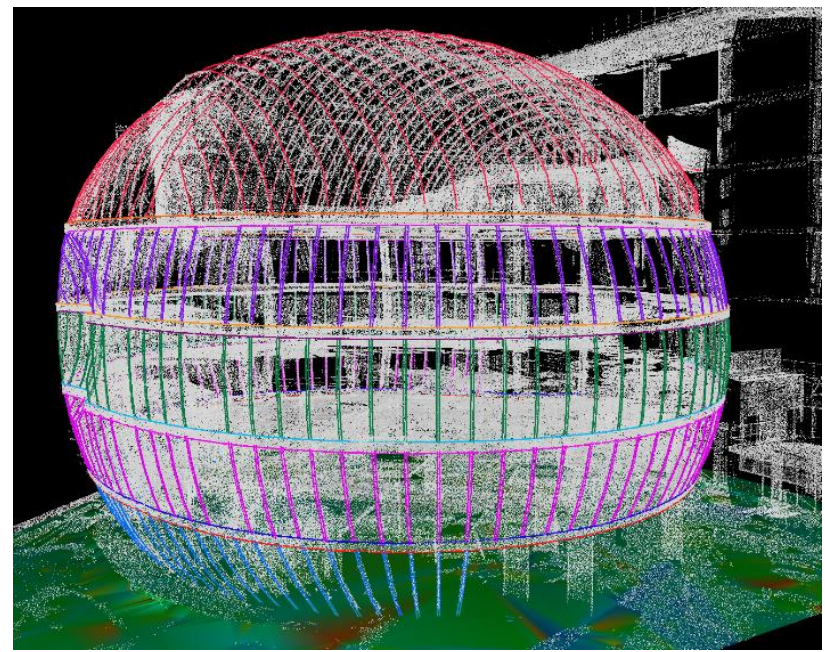

Figure 4. 3D point cloud of the mall with shell's design.

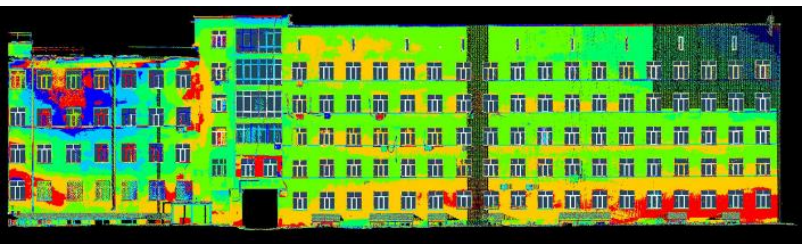

Figure 5. 3D point cloud of the building façade.

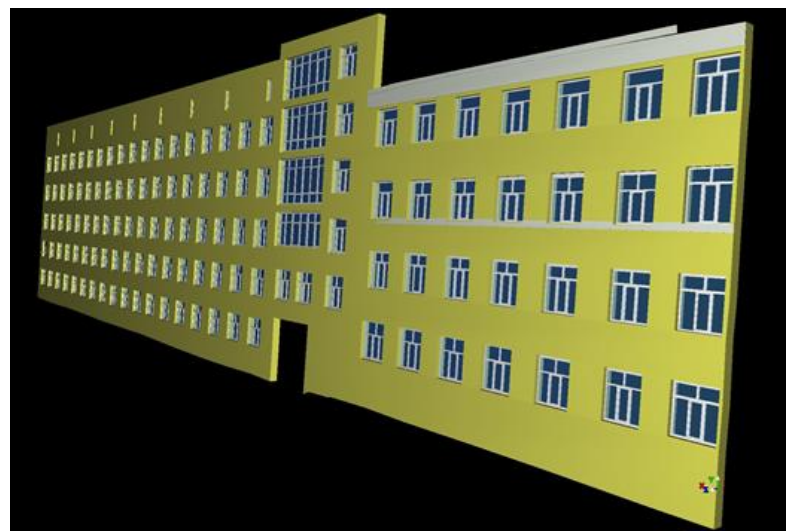

Figure 6. 3D design of façade panels.

The third example presents the case of facade reconstruction. After the building construction, the facades, as a rule, differ from the project, and it is impossible to design and install a hinged facade to finish the building covering. In Fig. 5, the building façade by scanning data is presented.

The different colors in Fig. 5 show the deviations of the façade from the design. It is clear that the deviations are distributed unevenly and have significant values. According to the results of the actual parameters of the façade obtained from surveying, the brackets, guides, and facade panels were designed (Fig. 6).

The panel sizes data were transmitted to the plant, where they were cut and adjusted to the actual sizes. A specification was being drawn up. The study has shown that the plant saved up to $10 \%$ of time and materials during production. Of importance that the panels were being installed without fitting works.

Those given samples prove the high efficiency of 3D geospatial technologies, particularly TLS, at the design stage.

\subsection{Construction}

Construction surveying embraces a vast number of processes on the construction site. The accuracy, reliability, and surveying capacity depend on the structure size, shape, and purpose. Mostly, this stage is the most time-consuming and laborious. That is the case when TLS comes in handy. Let's consider some examples of how TLS technology may help civil engineers to accept the right decision.

Building surveying is the most widespread of engineering surveying. The main downside of surveying by the total station is measuring a vast number of points. On the other hand, it frequently happens that one has to measure additional points that were not defined in a project or measurement program. The building in Fig. 7 demonstrates just the case when a number of measurements exceed thousands of points.

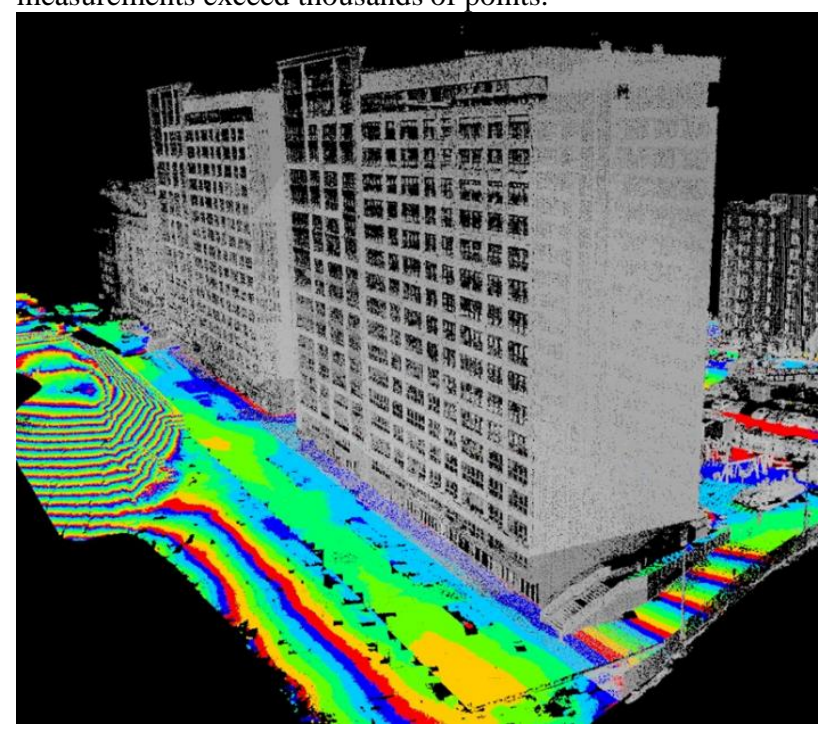

Figure 7. 3D point cloud of the building.

If additional measurements are mandatory, the surveyor must take the equipment and repeat the measuring procedure. However, there is no need for field measurements longer with the point cloud. One may open a point cloud or 3D model and grab the necessary points (Fig. 8). The measuring procedure has no difference from typical CAD software and may be carried out by workers just on the construction site. The new measurements then will be used in the construction process. But, at the same time, these measurements will be transferred online via the internet to the designer's office. In what follows, the designer makes appropriate corrections to the project and rearranges the BIM to the actual construction status (Fig. 9). Of course, such an approach is considerably faster than traditional surveying and 
promotes excluding the errors due to additional measurements on-site.

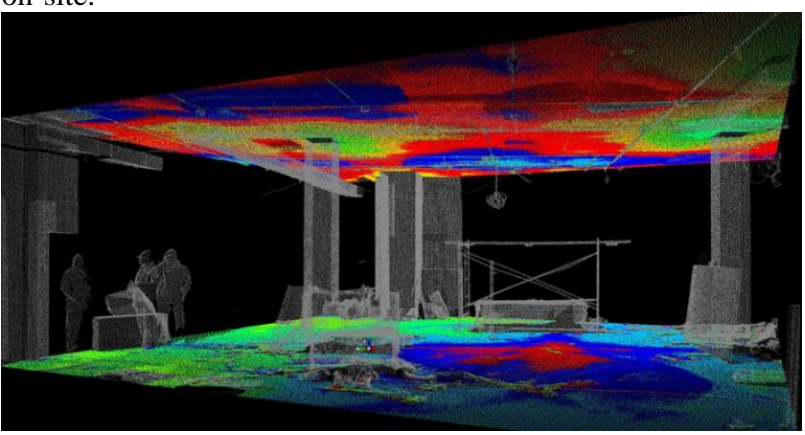

Figure 8. 3D point cloud for measurements.

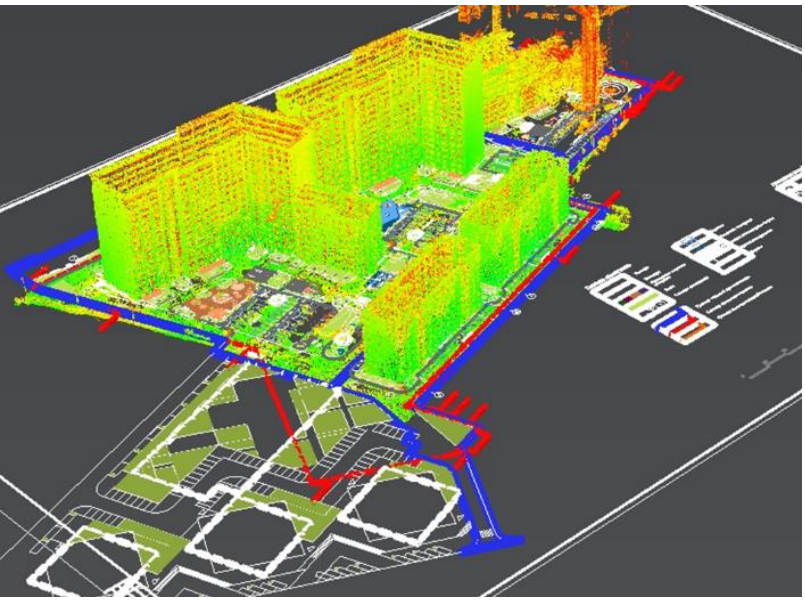

Figure 9. Fusion of 3D point cloud with BIM.

A cumbersome process is interior surveying for control surveys and further interior design. That is the case when TLS provides a complete picture of interior geometry with semantic information after modeling (Fig. 10).

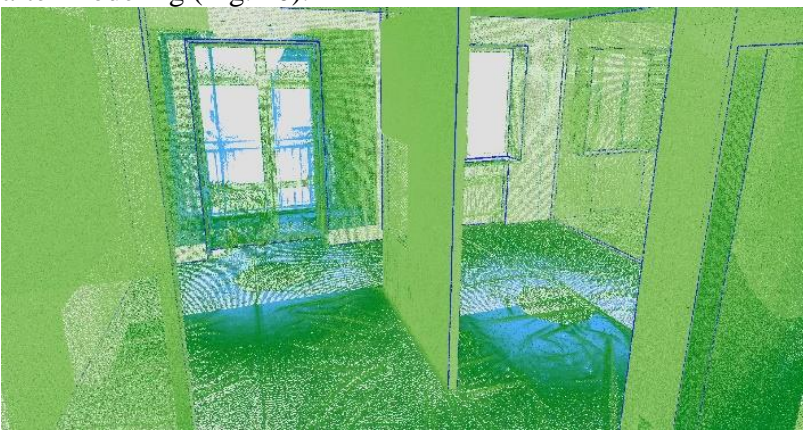

Figure 10. 3D point cloud with basic interior elements.

The modeling results are presented in Fig. 11.

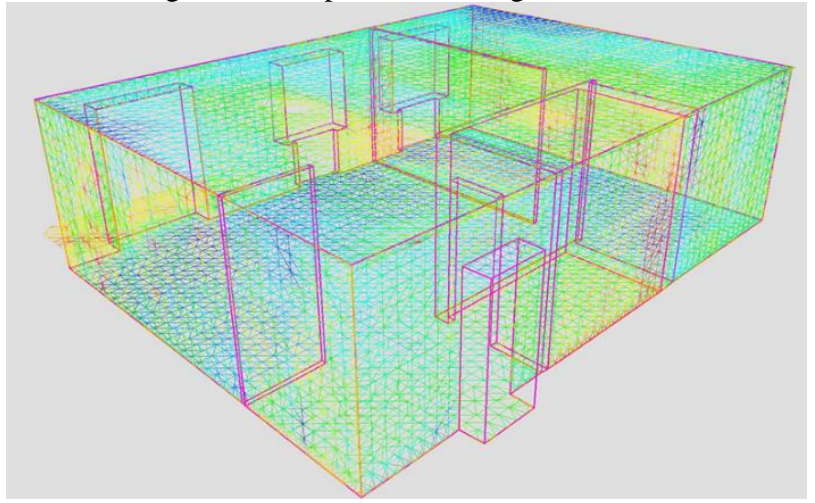

Figure 11. 3D modeling of the interior.
And finally, one example of how the results of interior surveying by TLS can be used for design. In Fig. 12, the point cloud of interior surveying is pictured.

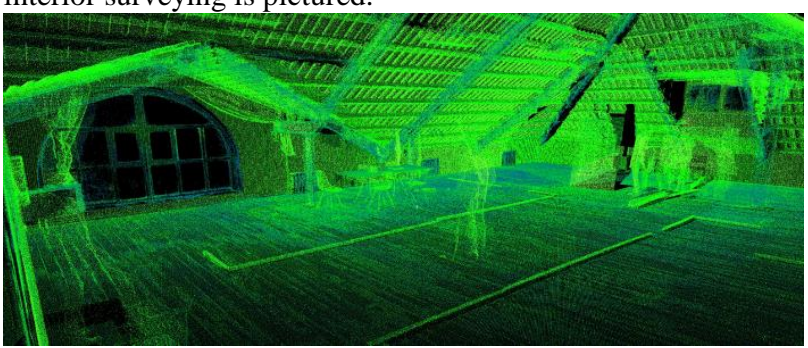

Figure 12. 3D point cloud for interior design.

The results of interior design are presented in Fig. 13.

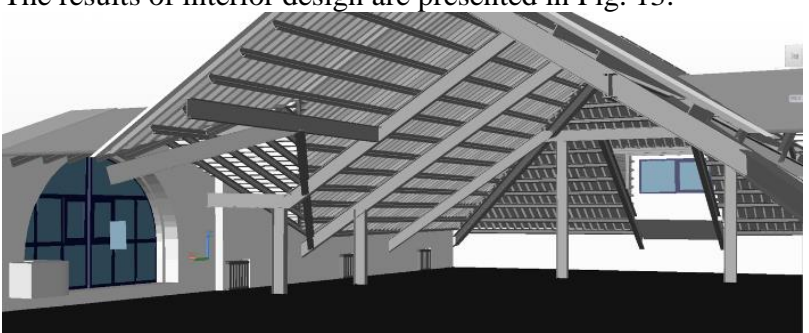

Figure 13. 3D modeling and design of the interior.

Therefore, TLS supports a building construction process at any step.

\subsection{Exploitation}

The next stage of a building life cycle is exploitation. At this stage, civil engineers pass their function to the exploitation engineers. However, the exploitation stage still needs the involvement of all participants in the construction process. Let's consider the process of decision-support for structures exploitation in the case of highway exploitation. Thanks to TLS data, it becomes possible to quickly simulate spatial data at the stages of cutting and laying all layers of the pavement, laying the leveling layer, the top layer, surface control after laying the top layer (Fig. 14), determine the deformations of the road surface and surface roughness (Fig. 15), control road construction equipment, control the deviations of the layer thickness (Fig. 16), control the work of structural divisions and subcontractors, control the consumption of building materials, etc.

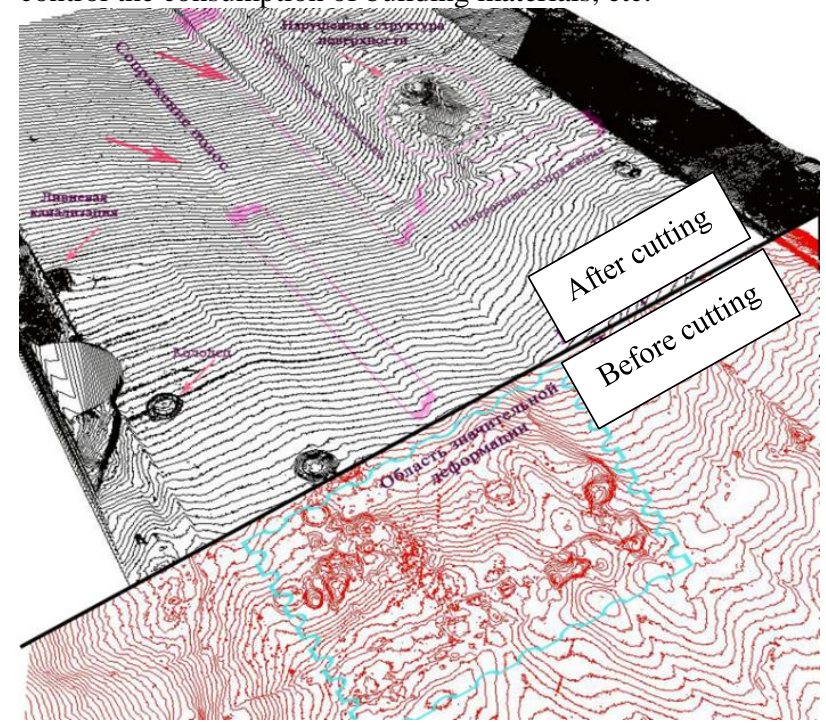

Figure 14. Comparison of the highway top layer before and after cutting works. 


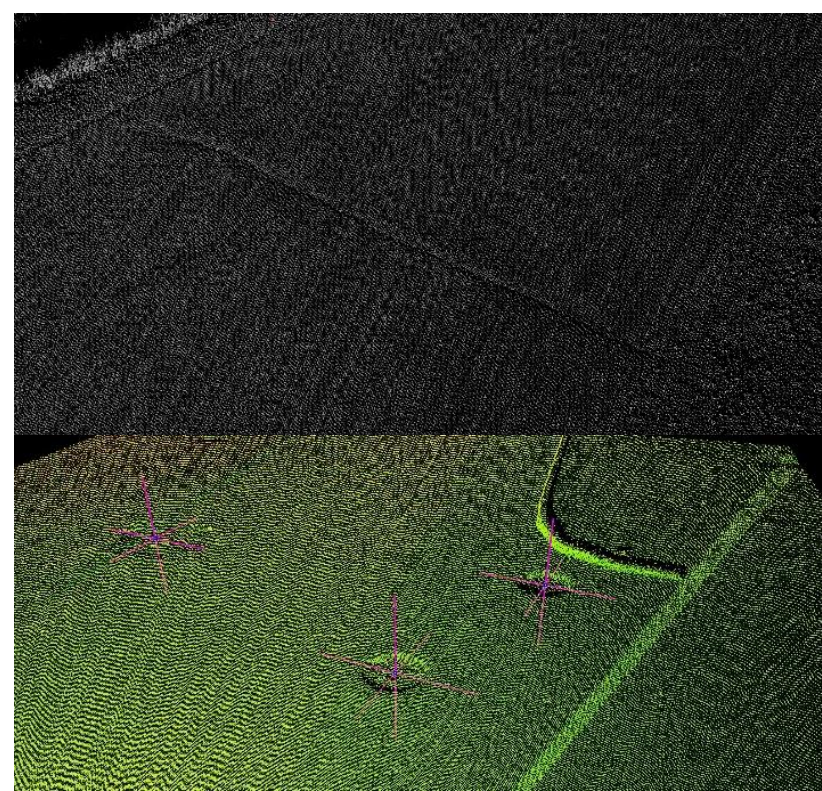

Figure 15. Determination of the size and position of bumps and potholes on the highway point cloud.

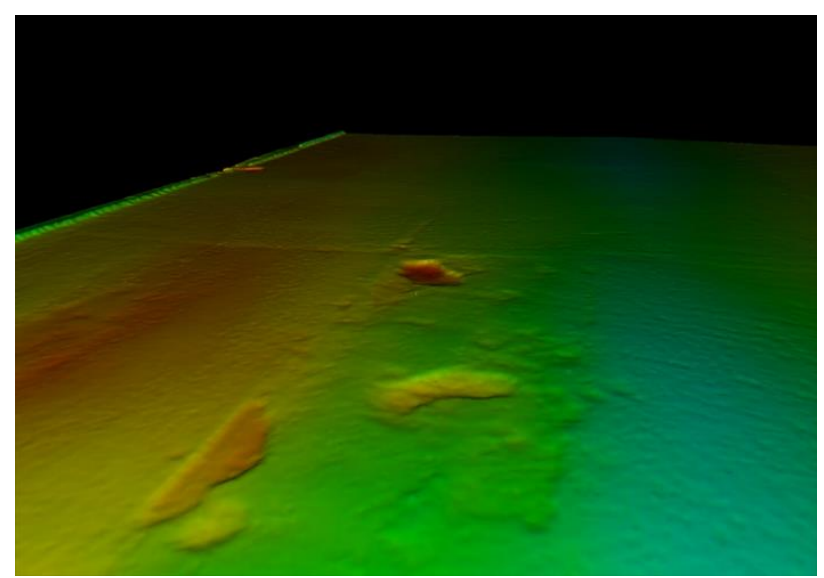

Figure 16. 3D model of road surface with potholes.

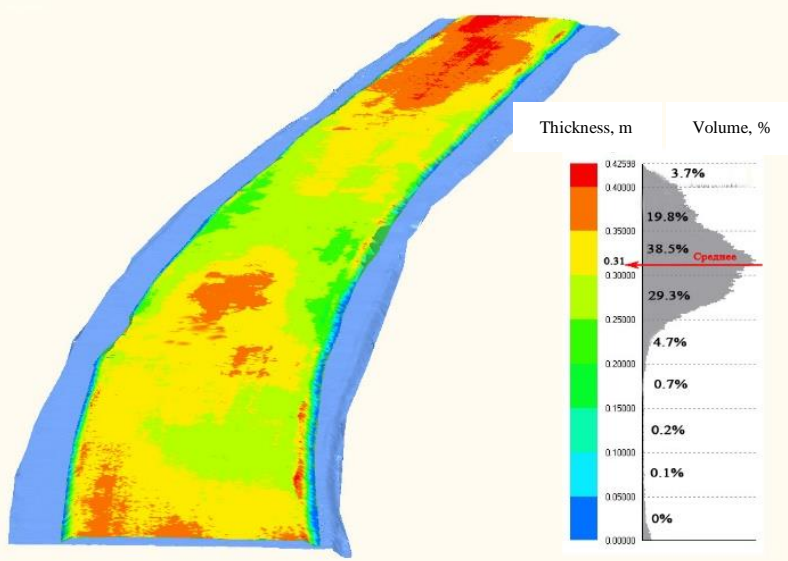

Figure 17. Distribution of the layer thickness deviations.

TLS allows the creation of detailed 3D models in a format that readily can be integrated into road BIM (Fig. 18).

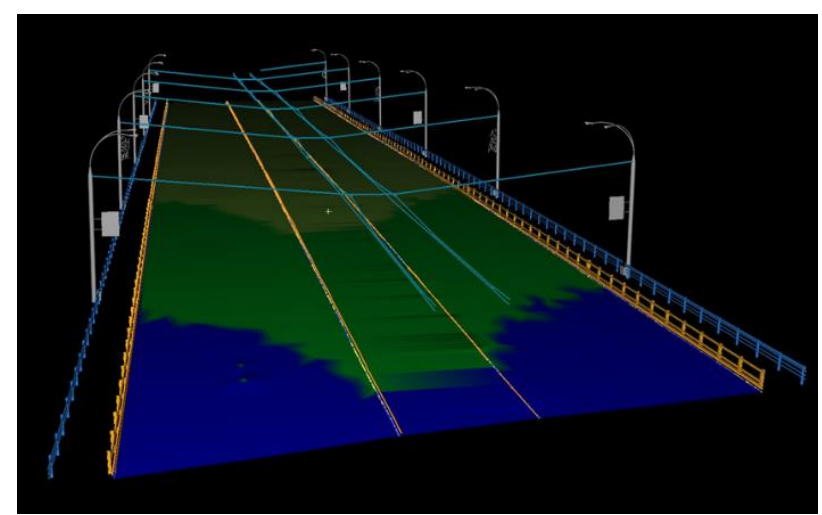

Figure 18. Road 3D model with infrastructure.

During the reconstruction process, roads may radically change their characteristics and parameters (sidewalks and bicycle paths appear, the width changes, lighting is installed, etc.). Regarding this, the task of certification of the highway, the creation of largescale digital maps or models, and their integration into the city's digital model will appear. No one needs to carry out timeconsuming field measurements and spend additional funds. In this case, a budget can be reduced several times.

The studies concerning the application of TLS pushed the authors to the idea of complete control. The concept of complete control will be given below.

\section{COMPLETE CONTROL CONCEPT}

\subsection{Complete Control Idea}

Before getting down to the idea of complete control, one needs to consider the modern concept of digital construction. Digital construction is part of the digital economy and the digitalization of all cutting-edge processes worldwide. Digital construction methods make it possible to fully implement BIM and provide complete control of the geometric parameters of the construction and operation of engineering structures. The implementation of the digital construction idea should embrace all stages of an object life cycle, including pre-design studies, design, construction, operation, and disposal (demolition). Regarding this, complete control allows determining the parameters of all structure elements without random sampling that it was before. The concept of complete control has become possible just after the dissemination of 3D geospatial technologies in civil engineering. Therefore, today, civil engineers got a chance to check the structure geometry in detail and not in general. Predesign studies include collecting all geospatial and other data digitally and their transfer for the design with real-time option (including in 3D). Some refinements or corrections of the previous studies are possible during the design stage. The principal stage is construction. At this stage, the concept of complete control brings to life. Let's consider the steps of 3D geospatial technologies application, namely TLS, and stand out the steps corresponding to complete control. Generally, the construction stage needs 3D geospatial technologies application for the following steps:

a creation of a geodetic network and a network of targets with known coordinates;

step-by-step scanning of a structure and obtaining models of the structural elements in 3D;

a fusion of design data in BIM with TLS data (in realtime). Complete control;

discrepancies determination between the project and the actual geometry of the structure elements, their estimation according to requirements. Complete control; 
delivering results to the services of customer, contractor, technical supervision, and designer;

marking the structural elements that do not meet the requirements, calculating volumes (dimensions, areas, volumes of concrete work, reinforcement volumes, etc.). Complete control.

documentation of received data (control surveys, crosssections, etc.);

management decisions concerning the elimination of construction defects;

engineering infrastructure scanning and comparing with the project, discrepancies determination, documenting all data, calculating volumes, making management decisions. Complete control;

surrounding territory scanning and comparing with the project, discrepancies determination, recording all data, calculating volumes, making management decisions. Complete control.

At the stage of the structure exploitation, the following steps are significant:

preparation and transfer of the structure model to the customer in BIM compatible format, an adaptation of data for use in operation; structure;

implementation of BIM during the operation of the

structure scanning at the stage of operation, monitoring the structure, determination of deviations from the project during operation, documentation of all data. Complete control;

quality assurance check. Complete control;

working out a project to repair and reconstruct the structure, scanning the structure to control repair and rebuilding. Complete control;

control;

repair and reconstruction of the structure. Complete

working out a project for the disposal of the structure.

Finally, at the stage of the structure demolition, the following steps are significant:

structure disassembling and bringing the surrounding territory to the design stage. Complete control;

territory scanning, documentation of the final results. Complete control;

designing the structure new life cycle.

As a case study, let's consider the application of complete control for a city building.

\subsection{Complete Control: A Case Study of Building}

The study has been accomplished for a seven-story building (Fig. 19). Complete control was being applied for the construction stage of the building.

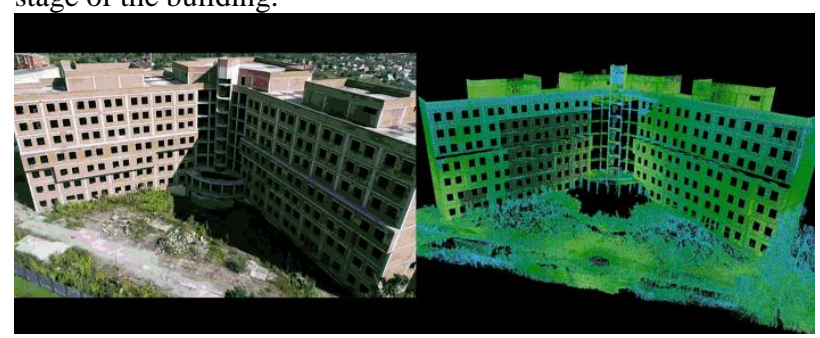

Figure 19. Imagery and point cloud of the studied building.

For each room of the building were measured the deviations of walls (Fig. 20), floors (Fig. 21), and ceilings (Fig. 22) from a plane. These deviations were presented in a convenient form that allows easily finding places with unallowable discrepancies marked in different colors. In addition to planarity deviations, the horizontal cross-sections with step $1 \mathrm{~m}$ were drawn (Fig. 23).

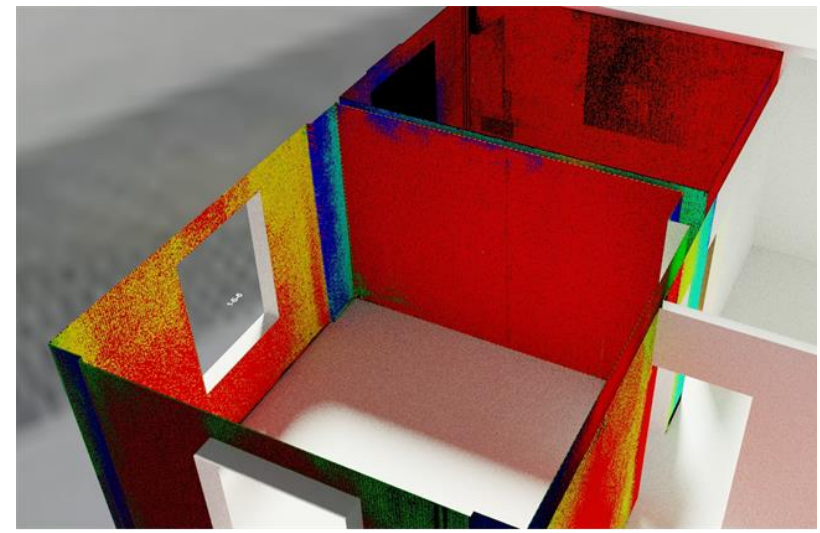

Figure 20. Wall deviations from a plane.

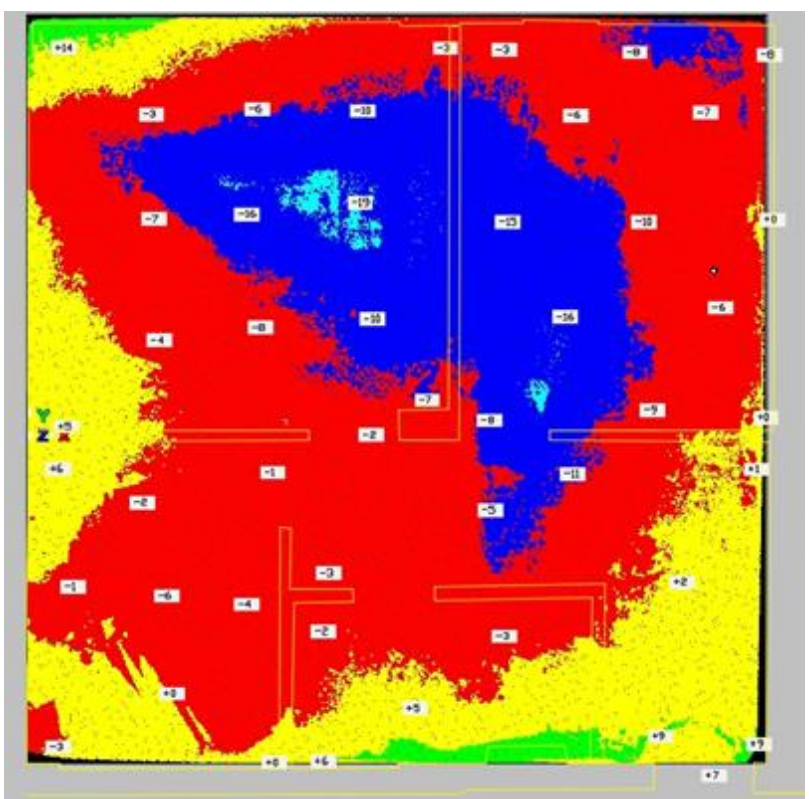

Figure 21. Floor deviations from a plane.

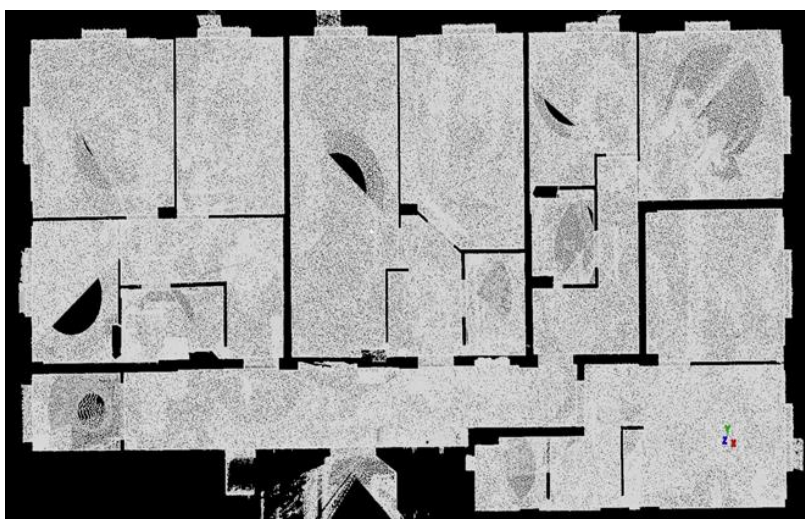

Figure 22. Ceiling deviations from a plane in greyscale.

Of importance is the determination of column displacements on each floor. By TLS data, a total of 650 columns were surveyed, and their displacements along the coordinate axis were determined. The example of a graph with columns' displacements is presented in Fig. 24. The second important parameter for the control is plate thickness. The plate thickness was checked for each floor. The example with thickness deviations is given in Fig. 25 . 


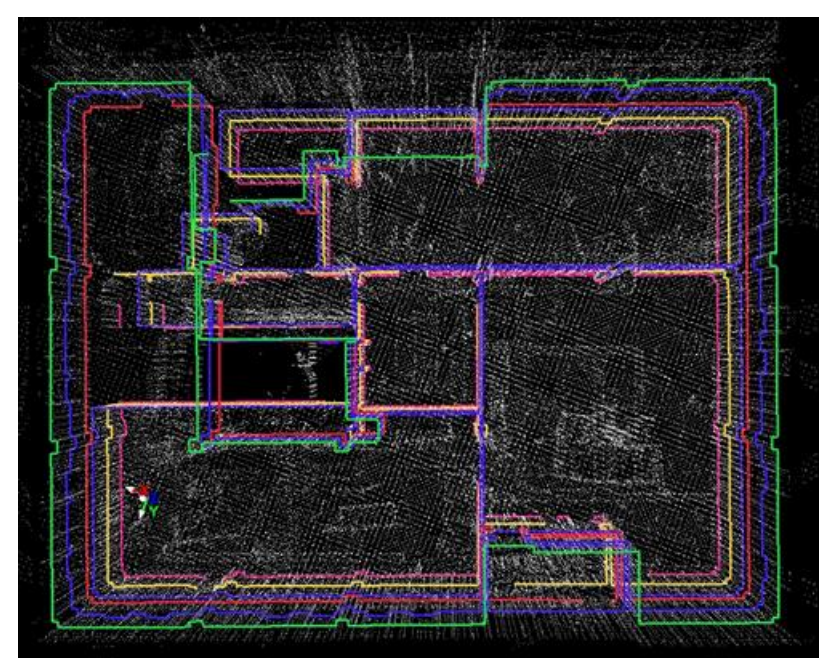

Figure 23. Horizontal cross-sections with step $1 \mathrm{~m}$.

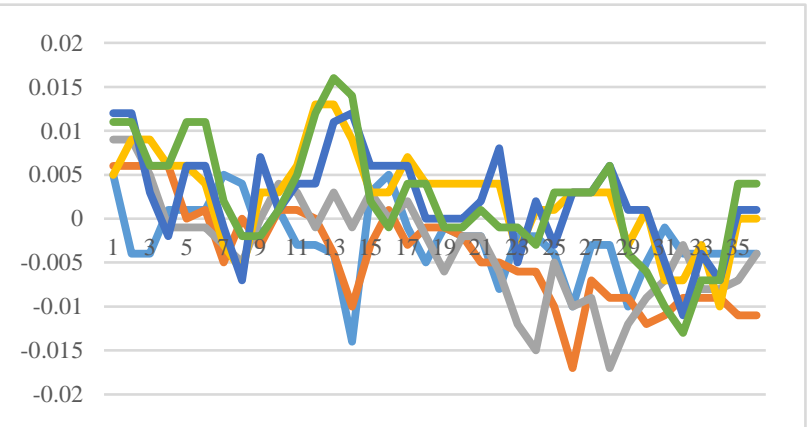

Figure 24. Column displacements in meters.

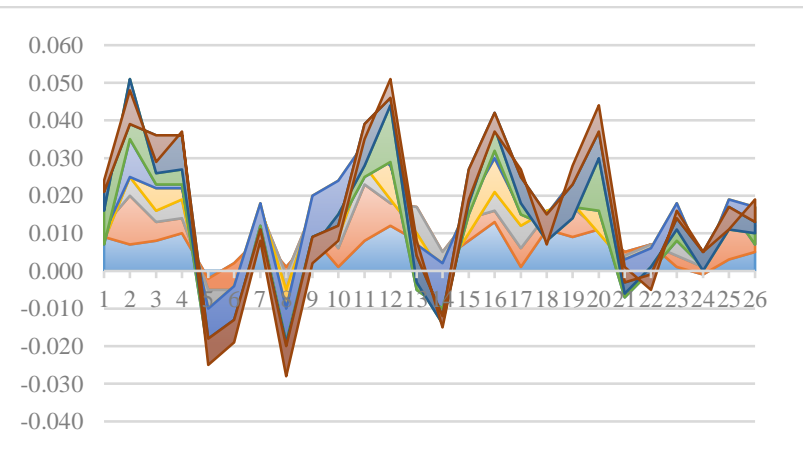

Figure 25. Plate thickness deviations in meters.

As one may see, complete control provides the construction process with sufficient and even redundant geospatial data. Moreover, complete control improves the quality of construction, ensures the construction and operation of the structure according to BIM, ensures the full compliance with the project, ensures compliance with quality assurance, provides complete control of volumes, provides continuous control of the geometric parameters, makes the construction processes "transparent", and provides risk reduction during construction (economic and technical).

\section{CONCLUSIONS}

The given paper considered the capabilities of $3 \mathrm{D}$ geospatial technologies in the decision-support process for the design, construction, and employment of engineering structures. The primary attention was paid to terrestrial laser scanning. TLS data were analyzed as a source of new unique data from the civil engineer's point of view. The primary aim of the study was twofold. The first was to TLS for industrial applications and BIM integration. The second was to address the concept of complete control. The study was based on vast hands-on experience and employed projects. The results yielded some interesting findings. "Digital construction" becomes digital at all building life cycle stages. This technology is a solution to the problem of applying BIM to the design, construction, reconstruction, and operation of facilities and continuous control of the geometric parameters. TLS data can be used as service data for various tasks. Thanks to 3D data, the building life cycle can become open and accessible to investors, developers, customers, and buyers. The application of digital technologies in the construction industry (and not only in the construction industry) can lead to revolutionary changes. The construction industry is becoming transparent in space and time, accessible and open.

Future studies will have to continue exploring the capabilities of 3D geospatial technologies in the decision-support process for different building life cycle stages. The research will have to investigate the role of other geospatial technologies and their integration with BIM.

\section{REFERENCES}

Aryan, A., Bosché, F., Tang, P., 2021: Planning for terrestrial laser scanning in construction: A review. Automation in Construction, 125, https://doi.org/10.1016/j.autcon.2021.103551

Berenyi A., Lovas T., Barsi A., Dunai L., 2009: Potential of terrestrial laser scanning in load test measurements of bridges. Periodica Polytechnica. Civil Engineering, 53/1, 25-33.

Berenyi, A., Lovas T., Barsi A., 2010: Terrestrial laser scanning - civil engineering applications. Int. Arch. Photogramm. Remote Sens. Spatial Inf. Sci., Vol. XXXVIII, Part 5, 80-85.

Hu, C., Peng, D., Lv, F., Sun, H., Zhao, T., Li, W., 2021: Application of Terrestrial Laser Scanner in engineering survey. In Proc. 2nd International Conference on Geology, Mapping and Remote Sensing IOP Conf. Series: Earth and Environmental Science. https://doi.org/10.1088/1755-1315/783/1/012084

Karagianni, A., 2017: Terrestrial Laser Scanning in Building Documentation. Civil Engineering and Architecture, 5(6), 215221. https://doi.org/10.13189/cea.2017.050603

Mill, T., Alt, A., Liias, R., 2013: Combined 3D Building Surveying Techniques: Terrestrial Laser Scanning (TLS) and Total Station Surveying for BIM Data Management Purposes. Journal of Civil Engineering and Management, Volume 19 (1), 23-32. https://doi.org/10.3846/13923730.2013.795187

Ninkov, T., Bulatović, V., Sušic, Z., Vasić, D., 2010: Application of Laser Scanning Technology for Civil Engineering Projects in Serbia. In Proc. FIG Congress 2010 Facing the Challenges Building the Capacity Sydney, Australia.

Shults, R., Annenkov, A., Seitkazina, G., Soltabayeva, S., Kozhayev, Z., Khailak, A., Nikitenko, K., Sossa, B., Kulichenko, N., 2021: Analysis of the displacements of pipeline overpasses based on geodetic monitoring results. Geodesy and Geodynamics, 12(6), https://doi.org/10.1016/j.geog.2021.09.005

Wu, C., Yuan, Y., Tang, Y., Tian, B., 2022: Application of Terrestrial Laser Scanning (TLS) in the Architecture, Engineering and Construction (AEC) Industry. Sensors, 22, 265. https://doi.org/10.3390/s22010265D 